\title{
A MÁQUINA E A ENXADA: ECONOMIA MORAL E ACUMULAÇÃO FLEXÍVEL NO TERRITÓRIO DAS CONFECÇÕES EM PERNAMBUCO, BRASIL
}

\author{
Berlano Bênis França de Andrade ${ }^{1}$
}

\section{A construção do território das confecções: trabalho e mobilidades ${ }^{2}$}

A origem do Polo de Confecções do Agreste de Pernambuco remete originalmente ao município de Santa Cruz do Capibaribe entre as décadas de 1950 e 1960 (Rabossi, 2008; Burnett, 2014) quando um conjunto de fatores a exemplo da crise na cotonicultura, a inviabilidade do acesso à terra para a reprodução da agricultura de subsistência ${ }^{3}$ e as constantes estiagens levaram homens e mulheres a optarem pela produção e comercialização de produtos derivados dos tecidos descartados pelas indústrias têxteis em São Paulo e na Região Metropolitana de Recife. Foi diante da circulação de pessoas (migrantes para os grandes centros urbanos) que objetos também percorreram longas distâncias ${ }^{4}$ e foram apropriados e ressignificados de forma a contribuir na reprodução social dos atores envolvidos. É dessa forma que se originou a Feira da Sulanca ${ }^{5}$ espaço que concentra a comercialização dos produtos nas cidades pernambucanas de Santa Cruz do Capibaribe, Toritama e Caruaru, fazendo com que os demais municípios se vinculem ao Polo na condição de lugares mais dedicados à produção das confecções naquilo que Lira (2011) caracteriza como uma divisão

\footnotetext{
${ }^{1}$ Universidade Federal de Pernambuco, Brasil. Email: berlanobenis@gmail.com

ORCID id: https://orcid.org/0000-0002-5409-3148

${ }^{2}$ O presente artigo apresenta e desenvolve partes de minha dissertação de mestrado em Antropologia defendida em 2017 sob a orientação da professora $\operatorname{Dr}^{\mathrm{a}}$ Josefa Salete Barbosa Cavalcanti.

${ }^{3}$ Embora não dê para explorarmos neste texto, é importante salientar que a especificidade fundiária na região historicamente foi marcada pela existência não só se minifúndios como também de microfúndios, conforme descreve Melo (1980).

${ }^{4} \mathrm{O}$ acesso às sobras descartadas pelas indústrias se dava ou quando comerciantes de Santa Cruz do Capibaribe os adquiriam nas fábricas pernambucanas ou quando os meios de transporte interestadual que levavam mão de obra migrante, ao retornar, traziam esses tecidos.

${ }^{5}$ A palavra Sulanca seria uma corruptela das palavras "sul" e "helanca", ou seja, a helanca vinda do Sul. Essa expressão, como argumentam Véras de Oliveira (2011) e Silva (2009), passou a marcar os produtos de baixa qualidade, de preços baixos e voltados às populações de baixa renda. A partir dos anos 2000 este aglomerado produtivo passa a se chamar Polo de Confecções do Agreste de Pernambuco. Essa mudança está relacionada com as estratégias de alguns atores locais, em especial os que conquistaram maior projeção, de tentar desvincular a imagem desse universo da feira da Sulanca, considerada por eles relacionada a produtos de baixa qualidade. Essa renomeação procura dar um ar de modernidade ao local.
} 
territorial do trabalho na região. Assim, como argumenta Véras de Oliveira (2011), a expansão das atividades do Polo possibilitou que se fosse compondo e recompondo os espaços rural e urbano: quanto mais se afirmou, mais exerceu efeito de atração nas regiões vizinhas de forma a conformar fluxos migratórios. As circulações de mão de obra e de objetos (peças de roupas e instrumentos para a sua realização como máquinas de costura), sejam no campo como na cidade, permitem a rápida expansão das atividades relacionadas a confecção.

\section{Mapa 1 - O município de Surubim}

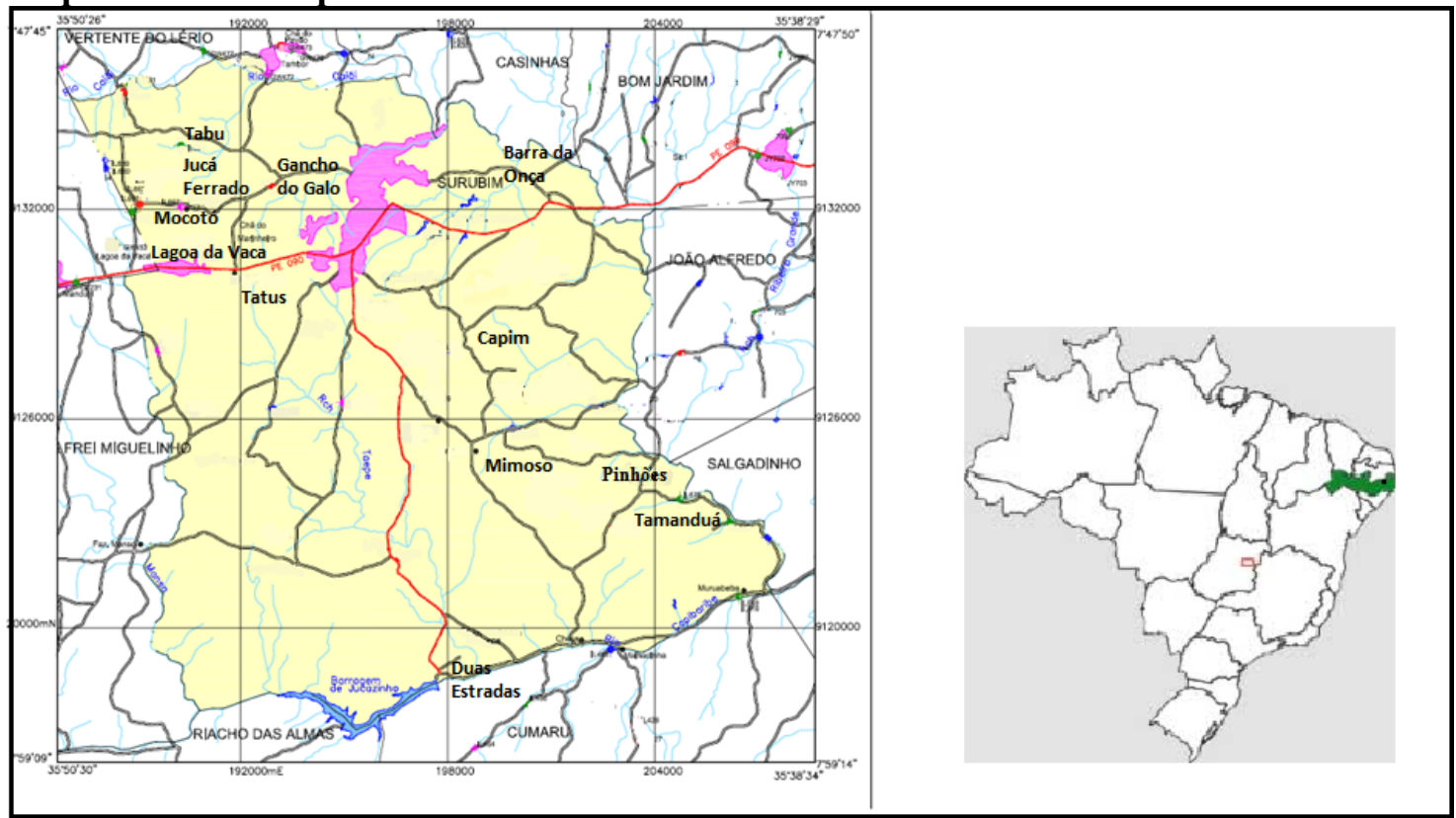

Fonte: organização de Berlano Andrade (2020).

Mapa 2 - Área de abrangência do Polo e os municípios agrestinos de Caruaru, Toritama, Santa Cruz do Capibaribe e Surubim 


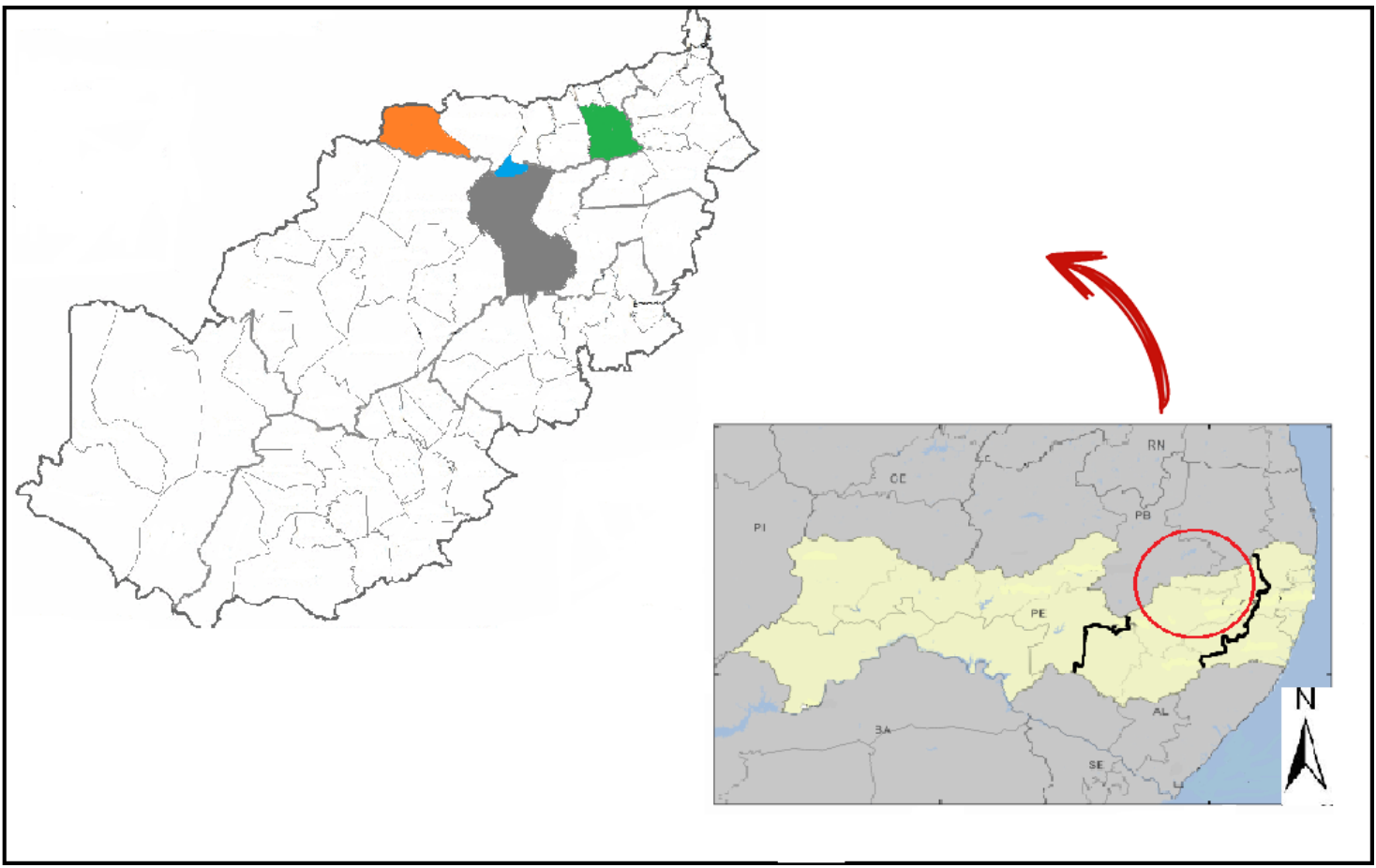

Caruaru (cinza) Toritama (azul), Santa Cruz do Capibaribe (laranja) e Surubim (verde). Fonte: Andrade (2017).

O objetivo do presente artigo é analisar um conjunto de práticas realizadas por trabalhadores situados em espaços rurais no âmbito do Polo de Confecções do Agreste de Pernambuco. Tais atores têm se relacionado com a emergência desse aglomerado produtivo de diversas maneiras: combinando atividades agrícolas com não-agrícolas, especializando-se na fabricação e venda roupas de diversos tipos, circulando (como migrações pendulares, definitivas e de retorno) em busca de trabalho e fazendo circular os produtos produzidos no interior das unidades familiares. A pesquisa foi realizada em algumas comunidades ${ }^{6}$ no município de Surubim, Pernambuco. Foram entrevistados trabalhadores que estão de diversas maneiras vinculados às atividades nas confecções como também se acompanhou reuniões do Sindicato de Trabalhadores Rurais, das Associações de Moradores e Agricultores e do Conselho Municipal de Desenvolvimento Rural Sustentável onde a inserção nesse tipo de trabalho também tem se dado pelas ações resultantes das pautas demandadas por algumas dessas entidades. $\mathrm{O}$ que nos chama a atenção é como vem se relacionando uma ordem moral camponesa com práticas que caracterizam a acumulação flexível do capitalismo. No nosso entender, a forma como o trabalho familiar é utilizado mobiliza uma economia moral de forma a engendrar relações não mercantis na produção e comercialização de mercadorias.

\footnotetext{
${ }^{6}$ Neste trabalho, os termos êmicos são destacados simultaneamente em itálico e negrito.
} 
A história do Polo de Confecções ${ }^{7}$ é uma história das mobilidades. A sua formação só foi possível porque entre os camponeses do Nordeste brasileiro as práticas de migração e combinação de atividades agrícolas com as não-agrícolas são generalizadas. Há uma substancial literatura que mostra como os deslocamentos foram e são - utilizados como estratégias de reprodução social de unidades familiares. Nas décadas de 1970 e 1980 vários autores apontaram a necessidade de trazer para o debate a compreensão de que a migração deva ser entendida, além de um processo de êxodo rural e transformação em trabalhadores urbanos, em um mecanismo que permite famílias camponesas de a utilizar como forma de manutenção de suas formas de vida. É aqui que se inserem as contribuições de Garcia Jr (1990), Menezes (2002), Scott (1986) e Woortmann (2009). Por meio desses trabalhos, observa-se a necessidade de tomar a perspectiva dos atores sociais produtores das redes que tornam possíveis as mobilidades. Com isso, torna-se necessário ir além das abordagens "estruturais" que procuram descrever meramente os processos de desenvolvimento regional e interregional anulando a agência dos envolvidos.

A década de 1990 tornou mais nítida uma tendência a uma profunda mudança nas estruturas migratórias na região onde hoje se localiza o Polo. Se antes, mais especificamente entre as décadas de 1940 e 1980, as migrações se caracterizavam por serem mais longas, durando meses e até anos; tinham áreas de origem e destino mais definidas e havia uma cadência entre mobilidades espacial e social, elas passam a ser mais curtas, pendulares e múltiplas nos seus locais de destino e se reforça o descompasso entre mobilidades social e espacial, percebidas deste os anos de 1980. De acordo com Menezes (2009), ao tratar das migrações no Agreste paraibano, a deterioração das condições de trabalho e moradia no Sudeste a partir dos anos de 1970 fez com que o trabalho na plantation açucareira em Pernambuco emergisse como meio concorrente de reprodução social. Já Fusco \& Vasconcelos (2010) apontam que entre os anos de 1970 e 2000 o Agreste pernambucano destacou-se não só como área de evasão da população como também de atração de emigrantes em termos proporcionais. Por sua vez, devemos destacar as contribuições de Gomes (2002) e Lyra (2005) que procuram

\footnotetext{
7 "Polo da Moda de Pernambuco" ou "Polo de Confecções do Agreste Pernambucano", como é mais conhecido, passou a ser usado no início dos anos 2000 em substituição a "Feiras da Sulanca". Isso é resultado de um conjunto de ações por parte do empresariado local em se dissociar da imagem da "sulanca" que remeteria aos produtos de baixa qualidade. Procurava-se, com isso, passar uma imagem de modernidade aos empreendimentos locais.
} 
abordar as redes sociais que se instalam e promovem a circulação de pessoas e retalhos. No caso de Lyra, a atenção é dada mais especificamente ao processo de retorno de migrantes a Pernambuco entre 1970 e 2000 ao município de Caruaru. Para ela, as redes de relações sociais estabelecidas e consolidadas pelas rotas de ônibus Caruaru-São Paulo-Foz do Iguaçu supõem uma teia de comércio tanto formal como informal que se estabelece entre o sul do país e o Agreste pernambucano que reforça a relação com a família e a própria economia familiar. Gomes (2002), ao investigar a atividade comercial de retalhos no bairro do Brás, em São Paulo, identifica entre os migrantes que iniciaram essa atividade pernambucanos, de Santa Cruz do Capibaribe e cidades circunvizinhas, que surgiram seguindo o fluxo de comércio uma vez que diariamente saíam caminhões levando toneladas de resíduos e retalhos e, no retorno, serviram como transporte para os migrantes. Para os migrantes que permaneceram em São Paulo, o comércio de retalhos se converteu em uma das formas ou condições para sua sobrevivência nessa cidade.

Pode-se afirmar, com isso, que o Polo se retroalimenta, em grande medida, das redes de trabalho e consumo informais existentes não só na região como no país. Tratase de uma dinâmica muito próxima daquilo que Ribeiro (2010) chama de "globalização popular" ou "globalização popular de baixo para cima", ou seja, considerando aqueles agentes sociais que, em geral, não são considerados nas análises sobre a globalização e que se encontram nos mercados populares produzindo e consumindo produtos acessíveis à maioria da população. Sulanqueiros, sacoleiros, trabalhadores migrantes de cidades vizinhas que se empregam em unidades produtivas precárias e sem regulamentação trabalhista exercem todo um arranjo que torna esse universo possível.

O Polo conforma uma região que reconfigura os fluxos migratórios que impactam tanto o campo como a cidade. Diante das crescentes dificuldades encontradas para a reprodução da agricultura familiar, o trabalho nas confecções surge como meio pelo qual é considerado diante da estratégia doméstica (Scott, 2014) das famílias rurais. E essa opção desdobra impactos nas relações familiares, na estrutura produtiva da propriedade familiar e nas mobilidades.

Para os agricultores de base familiar, as transformações decorrentes da emergência e ampliação da área de influência do Polo têm impactado de várias maneiras as suas formas de vida e de trabalho. As características presentes desse aglomerado de 
produção e comércio de vestuários como o trabalho familiar, domiciliar e informal permitem um conjunto de interações entre as esferas de produção agrícola e industrial que antes de se excluírem podem se relacionar e possibilitar a reprodução de um em função de outro. Desse modo, diversos arranjos são observados nos espaços rurais: migrações pendulares campo-cidade, retorno para as comunidades de origem diante da possibilidade de exercer o trabalho na costura naquelas localidades, diferentes complementariedades entre a produção agrícola e da confecção dentro do grupo doméstico etc. Assim, visualiza-se importante tomar os agricultores familiares como referência para compreender as origens e configuração do Polo.

A formação do território produtivo das confecções passa pelas redes construídas por homens e mulheres. Nesse sentido, é importante considerar as especificidades que aparecem na construção de estratégias entre os agricultores familiares diante desse processo. No nível dos espaços domésticos, é importante destacar como a mão de obra feminina tem sido arregimentada a ponto de exercer significativa expressão entre os que têm se dedicado às atividades na confecção. Nos espaços rurais, o trabalho na costura se configura em opção de ocupação na qual mulheres têm se inserindo, de forma a impactar as próprias relações no interior da unidade familiar, como a conquista de maior autonomia, tanto pessoal como monetária. Essas transformações nos padrões de mobilidade se relacionam com as próprias mudanças no interior das famílias, a exemplo do que diz aos papéis de gênero. No nível dos espaços de ação coletiva (Sindicatos de Trabalhadores Rurais, Associações de Moradores e Agricultores, Conselhos Municipais de Desenvolvimento Rural Sustentável), o Polo aparece como elemento na qual é considerado na elaboração de estratégias e alternativas que permitam, via articulações com os poderes públicos, o acesso a mecanismos de permanência e fortalecimento do trabalho no campo. Isso tem se manifestado seja quando entram na pauta das reuniões e assembleias dessas entidades demandas para cursos de costura industrial ou quando o PRONAF $^{8}$, voltado para o fortalecimento da agricultura familiar através de empréstimos a esses atores, é usado para a compra de tecidos e máquinas de costura. Esses exemplos mostram que essas entidades têm reconhecido o desafio de pensar políticas voltadas para as atividades agrícolas em um cenário em que o trabalho nas confecções se converte em opção mais acessível de renda além de uma possibilidade de mudança de vida, especialmente para os jovens.

\footnotetext{
${ }^{8}$ Programa Nacional de Fortalecimento da Agricultura Familiar.
} 
É diante dessas situações que se deve compreender que a reprodução do capital via o trabalho nas confecções não se dá pela anulação das esferas rurais, de produção agropastoril e de suas sociabilidades. Se não o contrário: por meio delas é que o trabalho pode ser realizado a custos mais baratos, que as políticas voltadas para o fortalecimento da agricultura familiar podem ser aproveitadas para o desenvolvimento de atividades não-agrícolas, que os espaços das reuniões das entidades dos agricultores, ou seja, de interação social, permitem que contatos sejam feitos e redes relacionadas ao trabalho nas confecções sejam tecidas.

\section{Algumas características do trabalho na confecção nas áreas rurais no município de Surubim ${ }^{9}$}

No Polo predomina as unidades produtivas familiares. Esse perfil parece ser propício para a sua expansão nas áreas rurais. Trata-se de compreender como essas características possibilitam a reprodução do trabalho faccionado nesses locais - e que tipo de relação laboral é configurada - e quais as suas semelhanças e diferenças com as atividades nas áreas urbanas, ou mesmo procurar entender os diversos níveis de integração rural-urbano que se estabelece via atividades na confecção e venda desses produtos.

Os trabalhadores com quem dialogamos destacam que foi a partir da rede de contatos, sejam parentes ou vizinhos, que iniciaram as atividades na confecção. Por exemplo, na comunidade ${ }^{10}$ do Jucá Ferrado, o crescimento dos fabricos $^{11}$ possibilitou que vizinhos começassem a trabalhar uns para os outros. Na comunidade do Mimoso, algumas pessoas que já estavam trabalhando na cidade vizinha de Toritama se convertem em contatos pelos quais outros residentes na localidade puderam acessar esse mercado de trabalho. Muitas vezes, quando procuram explicar o seu ingresso nessa atividade por meio dessas redes, acionam a categoria conhecimento. É o que mostra o depoimento de Beatriz ${ }^{12}$ (35 anos), moradora do Mimoso, ao falar sobre sua passagem

\footnotetext{
${ }^{9}$ Surubim localiza-se na mesorregião do Agreste de Pernambuco. É tido por Lira (2011) como o quarto maior município em produtividade.

${ }^{10}$ Comunidade é como localmente é referido as localidades que anteriormente eram chamados de sítios, que por sua vez guarda semelhança com os bairros rurais. Trata-se de um termo mais abrangente uma vez que, com a urbanização, algumas dessas localidades foram incorporadas às periferias da cidade e os sítios eram apresentados em oposição à rua, a área urbana e o centro administrativo do município.

${ }^{11}$ Os fabricos se caracterizam por serem unidades produtivas familiares, que contratam pessoas que, no geral, são parte de uma rede de relacionamentos, como parentes e vizinhos. Diferenciam-se pelo caráter informal e por certo funcionamento indissociado do local de moradia dos proprietários.

${ }^{12}$ Os nomes aqui usados são fictícios.
} 
durante algum tempo em Toritama onde trabalhou na confecção: “Aí eu conheci umas pessoas lá que eu tinha um certo conhecimento e fui”. Fabiano (22 anos), residente na Barra do Onça e que trabalha em um traveto $^{13}$ na cidade de Surubim, relata como sua passagem para essa atividade se deu por causa dos contatos em emprego anterior em um restaurante, no qual ele trabalhou por sete anos. Conforme outros funcionários iam migrando para o trabalho no ramo das confecções de vestuários, ele optou por essa atividade graças a essa rede:

Esses pessoal que trabalham lá [atual unidade produtiva onde trabalha] são muito amigos meus, sabe, muitos trabalharam comigo no restaurante. Ai sairam e foram pra lá. É tudo conhecido, fui para lá conhecendo todo mundo lá. Amizades já, entendeu, conhecimento já.

Esses casos sugerem que ao pensar nas redes que se constituem e permitem a circulação de pessoas, conhecimento é um elemento de identificação e reconhecimento entre as partes. Afinal, as redes não são tecidas entre estranhos. Reivindicar ter conhecimento é tornar evidente ser parte dessa interação ${ }^{14}$.

As redes de parentesco, vizinhança e conhecimento explicam a capacidade de tanto fazer circular pessoas do campo para a cidade como de integrar áreas rurais ao trabalho nas facções $^{15}$. Assim, as diferentes formas de trabalho que caracterizam o Polo ganham expressão nas diversas comunidades em Surubim. Nesse sentido, tem-se que considerar que cada local pode adotar diferentes produções e dentro delas diversas tarefas segundo uma divisão do trabalho. No Jucá Ferrado, predomina os fabricos e as facções relacionadas a eles e dedicados a produção de calças e shorts de baixo custo. Francisca (54 anos) oferece uma explicação dessa diferenciação da produção:

Tem, assim, a facção da gente é do tipo que pega [peças de roupas dos fabricos], mas é roupa de trabalho, os shorts. É o preço mais baixo, mas é uma peça que vende diretamente. Ai chama short de trabalho só os shorts. Ai essas peças a gente pega porque ela só pega a máquina reta, ai pronto, para quem já tem interloque $e$ overloque já pega outras peças para passar nela também mas a de trabalho não precisa. Aí o dono do fabrico é o que tem em casa. O fabrico que tem no Jucá é desse tipo de fabrico, é desses shorts. Aí só faz passar em casa, no fabrico deles, cortar, pegar de volta com a gente, passar na máquina com a overloque, botar o elástico e o cordão. Ai esse fabrico tem no Jucá. Aí eles são os fabricos de shorts de

\footnotetext{
${ }^{13}$ Traveto é uma facção direcionada para a atividade de travetagem. Travete é uma máquina voltada para a costura de bolsos, zíperes e laterais. Também é usada para casear e dar reforço nas costuras.

${ }^{14}$ Souza (2012) explora a presença dessa categoria entre os sulanqueiros em Santa Cruz do Capibaribe. No seu caso estudado, conhecimento aparece como a capacidade de acumular prestígio e ter confiança na região e, em decorrência, ter crédito entre os atacadistas de tecido. Isso expressa uma rede na qual também fazem parte a vizinhança e o parentesco.

${ }^{15}$ As facções distinguem-se dos fabricos pelas condições mais precárias e cumprem um papel de atender, sob a condição de subcontratadas, demandas pontuais das fabricas e fabricos.
} 
trabalho, eles produzem muito, mas, é do tipo que não dá tanto trabalho como o fabrico grande, que é o fabrico de jeans, que não são registrados, que é em casa. Esses fabricos que é de jeans, essas coisas precisa de lavanderia, para levar para a lavanderia, tem que ter todo tipo de registro, ter o CNPJ.

O investimento na atividade da confecção de jeans exige um capital maior em comparação a produção de roupas de baixo custo. A padronização das peças pode exigir um cuidado especial no corte dos tecidos, demandando um trabalho especializado, diferentemente dos fabricos de "roupas populares" em que geralmente os próprios confeccionistas cortam os tecidos. A necessidade de vários tipos de máquinas para montar uma peça de jeans - além de outras etapas como pregar botões, lavar e tingir vai demandar também um maior capital de giro. Assim, vários níveis de especialização surgem diante da cadeia produtiva das confecções. Pode-se pensar a partir daí duas consequências. A primeira é a que aponta um reforço para a utilização do trabalho subcontratado pelas fábricas ${ }^{16}$ e fabricos. Isso porque libera essas unidades produtivas de um peso maior de reinvestimento em instrumentos de produção. A segunda é que as diferentes atividades com seus graus variados de especialização permitem incorporar de várias formas possíveis a mão de obra. Francisca, esclarece que "as pessoas que não aprendem a costurar, pega para limpar peças”. Limpeza e bordado são atividades mais pontuais e que exigem menos especialização. São atividades que podem ser tanto constantes (a limpeza é uma das etapas finais na produção de roupas de jeans) como variáveis de acordo com épocas do ano (segundo o que Francisca relatou, o bordado em peças tende a aparecer no final do ano). Este último parece sugerir também que a presença das atividades da confecção também pode ganhar um aspecto de atividade complementar em determinadas épocas do ano.

Essa cadeia produtiva que se reajusta às possibilidades e potencialidades das diversas comunidades rurais se apoia também nas estruturas dos espaços domésticos. A remuneração do trabalho subcontratado é realizada em cima da encomenda: uma quantidade de peças é entregue e se acorda o tempo na qual o contratante irá buscá-las. Ao pagá-los, os donos das fábricas ou fabricos remuneram a unidade como um todo cabendo aos subcontratados administrar internamente o pagamento. Se, por exemplo, uma facção possui mão de obra externa à família, estes deverão ser pagos pelas suas

\footnotetext{
${ }^{16}$ As fábricas, por sua vez, se constituem formalmente, havendo uma dissociação entre a base operativa do domicílio dos patrões e por se basear na contratação do trabalho assalariado, seja em condições formais como informais (Véras de Oliveira, 2011).
} 
funções. Se predomina o trabalho entre membros da unidade familiar, tende a não haver uma remuneração fixa entre eles ${ }^{17}$.

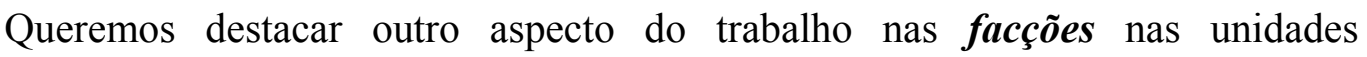
familiares em áreas rurais. Não se trata aqui de observar a reprodução de práticas do campesinato no espaço urbano diante de atividades não-agrícolas, mas de analisar nos espaços domésticos rurais como o trabalho para o Polo interage com essa ordem moral. Vários autores (Souza, 2012; Espírito Santo, 2013; Burnett, 2014) apontam que essa estrutura presente na Feira da Sulanca e em unidades produtivas nas áreas urbanas expressam uma sociabilidade oriunda das práticas dos sitiantes. Como visto aqui, as redes de parentesco, vizinhança e conhecimento mobilizam o acesso de pessoas para essas atividades e com a possibilidade dessa cadeia produtiva se organizar de forma descentralizada, temos uma configuração onde predomina o trabalho domiciliar.

Como argumenta Chayanov (1985), o tamanho e a composição da unidade familiar ${ }^{18}$ camponesa exerce sua influência na organização da unidade econômica tanto quantitativamente como qualitativamente. No seu interior, essa organização se expressa por meio de uma série de obrigações entre os membros da família. Estas são delineadas diante da divisão sexual do trabalho e sua relação com o espaço doméstico, como descrevem Heredia (1979) e Garcia Jr (1983).

A noção de ajuda constitui uma dessas obrigações. Na unidade familiar, são as tarefas que, nas palavras de Souza (2012), mobilizam "a participação de todos os membros da família para auxiliar na produção e na manutenção da economia doméstica" (: 112). Heredia (1979) mostra em sua pesquisa as diversas ajudas exemplificadas nos casos em que as crianças ajudam as mulheres em atividades como a alimentação e cuidado da pequena criação, limpeza no interior da casa ou quando vizinhas se dispõem a auxiliar mulheres que acabaram de ter filhos em alguma atividade

\footnotetext{
${ }^{17}$ Essa situação encontra paralelo com as pequenas unidades produtivas de lingeries nas áreas rurais de Nova Friburgo - RJ estudadas por Carneiro \& Pereira (2012). No caso por eles analisados, tende-se a remunerar o parente que não mora no mesmo domicílio. Os que habitam a mesma unidade doméstica não têm uma remuneração fixa. Segundo os autores, o trabalho dessas pessoas não é quantificado e na maioria dos casos é visto como ajuda. Por sua vez, Espírito Santo (2013) afirma que o trabalho com a família contém a prática de ajuda familiar.

${ }^{18}$ Chayanov aqui pensa em um modelo que não incluiu as unidades que contratam mão de obra.
} 
doméstica. Ou seja, essa obrigação moral organiza as tarefas no interior da unidade produtiva $^{19}$.

Nas comunidades rurais, a ajuda mobiliza as tarefas nas confecções. Um exemplo é o caso de Beatriz que ajuda o esposo nas atividades agrícolas, ou nas suas palavras "sempre que eu posso, eu ajudo". Mas no que diz respeito à atividade na confecção, na qual ela é a principal responsável na família, os filhos, um de 18 e outra de 5 anos, contribuem para a atividade: "Sim, trabalhamos eu e meu marido e meus filhos ajuda, assim, na hora de arrumar as peças, de cortar as linhas, de deixar tudo arrumadinho". A participação dos filhos menores também ocorre no caso de Mariana (34 anos) residente em Jucá Ferrado. Tendo 17 e 16 anos, eles ajudam pela manhã quando não estão na escola:

(...) porque eles estudam. Ai eles não costuram o dia todo, costura meio periodo até 11 h00 11h30. À tarde vão para a escola porque eu não quero que parem de estudar, porque hoje em dia sem estudo é dificil muita coisa.

Entre os interlocutores, a ajuda também ocorre entre os que trabalham na confecção em outros lugares como é o caso da filha de Francisca que tem 25 anos e que mora em outra residência. Como ela explica "A minha filha trabalha costurando também. Ela costura em casa, costura na rua, quando ela vem, ela me ajuda na costura. Quando ela tá, ela costura tudo e assim vai.” Nesse caso, a ajuda está presente nas redes familiares como uma das várias obrigações entre os parentes que, aqui, já não ocupam o mesmo domicílio.

Os casos aqui relatados sugerem a existência de mecanismos fundados numa ordem moral que permite o uso do trabalho familiar na confecção. Os mesmos que orientam tarefas nas atividades agrícolas. Pensando o caso dos sulanqueiros em um bairro popular em Caruaru, Espírito Santo (2013) destaca a oposição entre trabalhar com a família e com os de fora sendo a confiança um critério importante, principalmente em um universo caracterizado pela informalidade. $\mathrm{O}$ trabalho com a família, vizinhos e conhecidos é, segundo um dos interlocutores do autor, uma busca pelo trabalho por conta própria.

\footnotetext{
${ }^{19}$ Silva (1995), em sua pesquisa sobre a produção familiar do bordado em Passira, Pernambuco, destaca que ajuda funciona como forma de socialização do aprendizado dessa atividade.
} 
Essa constituição, familiar e informal, tem permitido a reprodução precária das relações laborais. A subordinação aos acordos informais de trabalho coloca os trabalhadores das confecções em situação de vulnerabilidade. Se por um lado, um subcontratado tem que seguir os padrões das peças de forma a garantir uma qualidade no produto, eles não podem exigir como contrapartida regulamentação nas relações trabalhistas $^{20}$. E no interior da família, como destaca Espírito Santo (2013), torna-se ambíguo o par ajuda/exploração.

A persistência da informalidade, segundo Véras de Oliveira (2011), é um dos elementos constitutivos dos Polo e tem facilitado a reprodução dos empreendimentos de diversos portes ao mesmo tempo que esta característica inibe uma incorporação mais ampla dos empreendimentos locais à dinâmica capitalista. Segundo dados do SEBRAE (2013), nos dez municípios analisados, 80\% das unidades produtivas são informais enquanto apenas $20 \%$ formais. Ainda segundo esses dados, Surubim apresenta baixa taxa de informalidade, comparado com os demais, tendo $67 \%$ informais. Esses dados confirmam que a informalidade predomina nas facções. Como destacam Lima \& Soares (2002) o caráter familiar da produção junto a uma estrutura que facilita a "troca de emprego", ou seja, leva os subcontratados a mudarem de subcontratantes de acordo com as ofertas, explicam este perfil informal no Polo.

\section{Dos diferentes papéis atribuídos à ação coletiva}

Como atividade não-agrícola, que vem redefinindo territórios e estruturando o mercado de trabalho nas áreas rurais, o trabalho na confecção se constitui em um elemento ambivalente na afirmação de uma determinada ruralidade pelos atores envolvidos. Em uma das formas pelo qual acessamos o campo da pesquisa, via as entidades representativas dos agricultores familiares, as pessoas com quem estabelecemos contato nos apareciam em um primeiro momento como dirigentes destas. Por sua vez, o contato estabelecido através de um técnico do Banco do

\footnotetext{
${ }^{20}$ Infelizmente não poderemos explorar com mais fôlego as ambiguidades das relações de trabalho entre contratantes e subcontratados nas confecções. Mas destacamos que diante desse universo de relações informais pudemos perceber mecanismos muito próximos ao que Scott (2002) entende como estratégias cotidianas de resistência. Elas aparecem quando subcontratados "comem" tecidos, ou seja, gastam uma quantidade maior no corte de peças ou quando buscam mais de um contratante como forma de evitar uma dependência a um único fabrico ou fábrica.
} 
Nordeste do Brasil nos levou a contatar pessoas que necessitam preservar algum nível de atividade agrícola como critério para manter o acesso ao crédito rural. Esses casos mostram como diferentes relações e papéis desempenhados em cada esfera social estão presentes quando a atividade na confecção se torna alternativa de trabalho.

Como nos relatam, "a sorte de muita gente é o empréstimo". Para muitas pessoas o crédito rural tende a ser o meio mais fácil de fortalecer seu pequeno empreendimento. Em função disso, desistir de manter uma atividade agrícola acarreta a perda dessa garantia.

Muitos também são sindicalizados e contam com a futura aposentadoria como uma garantia de estabilidade. Em sua pesquisa, Milanês (2015) destaca que a formalização do trabalho na confecção é percebida de forma ambivalente pelos trabalhadores com quem encontrou. Segundo a autora, a regulamentação da relação de trabalho pode implicar um obstáculo aos direitos enquanto agricultores. Ainda de acordo com a sua investigação, entre quase a totalidade dos seus entrevistados, assinar a carteira de trabalho é percebido apenas como uma garantia de duas coisas: salário mínimo e aposentadoria. Outros direitos trabalhistas, como férias, seguro-desemprego e licença maternidade eram mencionados por poucas pessoas e mesmo assim sem saber ao certo o significado e como funcionam. No caso por nós analisado, contudo, várias garantias são debatidas e às vezes orientadas para o acompanhamento jurídico dentro dos espaços de representação dos trabalhadores rurais.

Em relação às pessoas que estão engajadas nos espaços de ação coletiva, a relação com a atividade na confecção surge na construção de pautas nas reuniões. Quando se discute a diversas formas de alternativas ${ }^{21}$ aos limites impostos a reprodução da agricultura de base familiar, surgem propostas como as de cursos de costura industrial como possibilidade de geração de outro tipo de renda.

O que se pode argumentar é que a depender da circunstância um papel ou outro é acionado estrategicamente como forma de garantir a reprodução social da família. Embora algumas pessoas tenham se dedicado prioritariamente à confecção, em determinados momentos ser identificado como agricultor familiar possibilita o acesso

\footnotetext{
21 Nos espaços de ação coletiva (Sindicato de Trabalhadores Rurais, associações de agricultores e Conselho Municipal de Desenvolvimento Rural Sustentável) a alternativa é sempre acionada em contraposição aos problemas apresentados, a exemplo da seca.
} 
a garantias que conjuntamente com o trabalho na costura permitem equilibrar as contas familiares ou garantir a reprodução do trabalho nas confecções.

Van Velsen (2010), argumenta que em uma sociedade o indivíduo terá que optar entre várias normas contraditórias:

Em todas as sociedades existem incongruências e contradições entre os vários conjuntos de normas nos diferentes campos de ação. Um problema que os membros de qualquer sociedade devem resolver é o de viver com tais incongruências por meio da manipulação de normas, de forma a que as pessoas possam continuar a viver juntas em uma ordem social. (: 442) [destaque nosso]

Pode-se, a partir dessa discussão, demostrar como as diversas situações em que se encontram os atores aqui analisados os fazem "manipular papéis sociais" de acordo com determinada situação. Uma costureira não é apenas costureira. Ela é mãe, colega de trabalho na confecção, agricultora, delegada sindical, dirigente da associação local e membro de uma comunidade religiosa. Quando a questão central é o meio por onde se pode garantir a sobrevivência, vão sendo acionados cada um desses papéis: nos espaços de sociabilidade, procura-se mobilizar as redes; frente às entidades que garantem direitos aos trabalhadores rurais, deve-se se engajar na construção de uma identidade coletiva enquanto agricultora familiar. Assim, o trabalho na confecção encontra uma forma de penetração e reprodução no espaço rural quando é "manipulado" estrategicamente junto com outras situações.

Tal observação reforça a percepção de que a acumulação do capital via o trabalho na confecção nesses espaços ocorre se apoiando em vários mecanismos. Um deles é o aproveitamento da organização social do trabalho que reproduz uma estrutura comum, a forma sitiante. $\mathrm{O}$ trabalho entre parentes e vizinhos e uma possível reserva de alimentos vinda da pequena produção permitem baratear o custo da força de trabalho. Outro mecanismo é o aproveitamento do microcrédito rural para financiar a atividade na confecção. Por fim, os espaços de sociabilidade atuam como pontos onde são construídas parcerias e redes para o trabalho na confecção. Quanto mais há o esforço para estimular a organização dos agricultores familiares, mais propício fica a construção de eixos por onde circularão informações nas quais permitirão as pessoas melhor atuarem diante das situações encontradas.

Em outra comunidade, Gancho do Galo, pode-se observar como se materializa a construção de uma territorialidade envolvendo diversos agentes e tensões. 
Acompanhando uma das reuniões ordinárias da Associação de Moradores, pudemos observar como a construção de sua agenda de atividades reflete os diversos meios pelos quais os associados procuram se fortalecer. Nesse espaço são tratados temas diversos como a organização da documentação que comprova a condição de agricultor. Esse documento permite que o seu portador possa entrar com o processo de aposentadoria, licença maternidade ou adquirir o $\mathrm{DAP}^{22}$, documento que assegura o produtor rural a obtenção do financiamento pelo PRONAF. Através da associação também são discutidos o acesso a programas e parcerias como as que permitem o corte da terra no inverno, a distribuição de sementes e a construção de cisternas.

Nesse caso, a costura surge como demanda de um público local. Interessante observar que durante a reunião em que estávamos presente, quando foi questionada a ausência dos moradores de uma das comunidades que integram a Associação, a resposta dada pela diretora foi de que "deviam estar costurando". Essa observação indica que o trabalho na confecção acaba por influir na rotina da própria Associação.

\section{Articulações produtivas e esferas morais}

O trabalho na confecção se converteu em elemento a mais na configuração de espaços considerados rurais. A sua relevância se dá por ser compreendido por vários atores locais - de trabalhadores do campo e suas representações de classe aos representantes de diferentes esferas do Estado - como possibilidade de saída às limitações impostas à reprodução dos agricultores de base familiar.

Para analisar como as atividades vinculadas à confecção ganham forma nas áreas rurais, há que se considerar como ela se relaciona com as diversas sociabilidades características do universo rural, em especial relacionadas às atividades agrícolas. Em Surubim, apresenta-se tanto unidades familiares que se especializaram na produção de peças de roupas como as que dividem este tipo de trabalho com o agrícola.

No Jucá Ferrado, ao questionar Helena se dá para viver só da agricultura, ouço uma contundente negativa. Nas suas palavras "Não tem condição... tem que ter outra renda para comprar outras coisas: uma carne, sardinha...”. Contudo, é preciso especificar as unidades familiares no que diz respeito ao peso que as atividades agrícolas têm na economia doméstica. No caso da família de Helena as atividades na

\footnotetext{
${ }^{22}$ Declaração de Aptidão ao PRONAF.
} 
criação e plantio exercem um significativo ganho na renda familiar. Além da plantação, que mobiliza mão de obra no inverno, há algumas criações de bovinos, suínos e caprinos, ou seja, atividades mais constantes ao longo do ano ${ }^{23}$. Se no primeiro a produção é voltada para o consumo interno, o segundo constitui uma fonte de renda monetária que é adquirida com a venda dos animais.

A criação, o comércio e a produção de gêneros alimentícios como milho e feijão para a venda estabelecem um circuito comercial que passa a coexistir com o da produção de vestuários no interior do espaço doméstico. Os casos analisados mostram que os circuitos se diferenciam, a começar pela sua extensão. Se, por um lado, a produção de peças de roupas da família de Helena estabeleceu contatos até Minas Gerais, a venda de gado ou de caprinos, no máximo, se estenderá ao Sertão, sub-região vizinha no Nordeste, conforme nos relatou outro criador que estava iniciando uma pequena unidade de produção de peças de roupas na comunidade dos Tatus. A circulação do produto da confecção tende a ocorrer de forma mais rápida e numa extensão maior em comparação àqueles dos animais criados nas pequenas propriedades da região. A rotação do capital vinculado à produção de vestuário se apoia nas transformações no território em que o Polo reorienta os fluxos de mão de obra e mercadorias. Integra espaços rural e urbano e define uma divisão territorial do trabalho de forma a dinamizar a produção e o escoamento dessas mercadorias via a grande participação de pequenas unidades produtivas. No que diz à produção agrícola, excetuando-se os grandes proprietários e casos de organização associativistas da produção ou comercialização, os pequenos produtores rurais se veem em condições mais restritas de escoar sua produção, quando não dependem dos atravessadores ${ }^{24}$.

Nos debates sobre migrações no Nordeste, uma das argumentações postas é a de que o ato de migrar não constitui uma fuga, mas sim uma resistência (Scott, 1986). Isso quer dizer que ante as limitações de reprodução social das unidades familiares, migrar configura uma maneira de manter vínculos com as propriedades de origem via o assalariamento em outras atividades (Garcia Jr, 1990; Woortmann, 2009). O caso descrito logo acima mostra, no entanto, que uma outra possibilidade de se fixar na

\footnotetext{
${ }^{23}$ Há também produção de palma para a alimentação dos animais.

${ }^{24}$ Há que se considerar, contudo, as características das mercadorias. Os vestuários são de fabricação mais rápida, de alguns dias, ao passo que para um animal estar pronto para a comercialização, levam-se semanas, meses.
} 
localidade, do ponto de vista das mobilidades, é estabelecendo outros circuitos de forma que uma determinada produção na unidade familiar possa circular penetrando por outros territórios e estabelecendo ligações com outros atores. Em outras palavras: antes, uma forma de tentar permanecer era através da migração temporária; hoje, pode-se também procurar se fixar na localidade fazendo com que sua produção circule cada vez mais longe e de forma mais rápida, no que se compreende como indispensável para a reprodução do capital (Harvey, 2011). Nesse sentido, observa-se que o trabalho na confecção influi na conformação do território rural. Com esse exemplo, percebe-se que é apressado argumentar que essas diversas atividades não-agrícolas implicam uma desfiguração do espaço agrário quando sua relação é na verdade ambígua podendo estabelecer elementos para a sua reprodução.

A maioria das unidades familiares que visitamos mantêm a produção agrícola basicamente para o consumo interno como no caso Francisca, no Jucá Ferrado:

- O que a você planta?

- Milho, feijão, limpei tanto mato esse ano. Ai botamos roçado em Lagoa da Vaca, na terra que tem, que é herança de meu pai.

- Você planta só em Lagoa da Vaca ou tem terra aqui?

- Aqui tenho o quintal de casa, que tem o que, se eu tivesse lucrado ${ }^{25}$ mesmo acho que tinha secado até milho naquele roçado, 53 metros de fundo, é grande. Ai lá [Lagoa da Vaca] plantei também. Ainda lucrei um jerimum. Ai pronto, ai a gente planta tudo: milho, feijão, faz uma horta no roçado. O pobre só planta desse jeito.

Na propriedade localizada na comunidade da Lagoa da Vaca, além do esposo e filhos de Francisca, trabalham em parcela própria outros parentes, como irmã e tio. Trata-se de um tipo de atividade que ocorre no inverno, ou seja, não é uma atividade que emprega mão de obra o ano todo ou que o retorno da produção seja lucrativo. Ainda de acordo com ela, uma característica no Jucá Ferrado é que os moradores plantam em terras descontínuas as suas casas e em propriedades de outras pessoas. O quintal, uma pequena extensão de terra que fica atrás das casas, permite uma possibilidade de plantio ou de pequena criação. Mariana, na mesma localidade, cria galinhas e porcos. Estes, contudo, constituem uma renda monetária para a sua família. Na comunidade, algumas pessoas preferem criar porcos e comercializar a sua carne diretamente pois consideram mais lucrativo do que vender o animal vivo a um atravessador.

\footnotetext{
${ }^{25}$ Aqui, lucrar se refere ao retorno, não monetário, da atividade investida. De forma semelhante, é usada a expressão apurado, embora esta apareça também para se referir ao retorno monetário, como observamos nos termos usados pelos costureiros e vendedores no Polo.
} 
Beatriz também destaca o peso das atividades agrícolas no orçamento familiar. "Eu crio galinha para o consumo de casa mesmo", diz. Como revela, o peso da atividade na confecção tende a influir na relação com o trabalho agrícola: “Até porque a gente nunca teve tempo de botar e de cuidar de um roçado grande pelo trabalho que a gente tem em casa pela costura. Aí é pequeno, mais para o consumo".

Esses casos refletem um processo de diferenciação interna do campesinato em que uma parcela tende a depender, mais que outros, de atividades externas ao trabalho agrícola familiar. Nesse aspecto, o trabalho na confecção emerge como uma possível opção dentre outras que existem, a exemplo do assalariamento nas grandes cidades, como Recife e São Paulo. Assim, tem-se que orientar o olhar não em torno da hipótese de uma "descampenização-proletariação" mas dos mecanismos constantes de reprodução de formas de vida e trabalho tanto nos espaços agrários como de uma atividade industrial $^{26}$.

A expansão das atividades relacionadas à confecção nas áreas rurais reflete a incorporação de uma mão de obra que se apresenta como disponível ante os limites relacionados ao trabalho agrícola. Isso explica a permanência, e em algum grau a reprodução, de uma determinada sociabilidade característica de uma ordem moral entendida como camponesa. Outro aspecto é que o trabalho agrícola permite algum nível de barateamento dos custos da força de trabalho dedicada à confecção. Morando na cidade, um trabalhador assalariado em uma fábrica ou integrantes de uma facção tende a depender exclusivamente do rendimento nessas atividades. No campo, uma atividade pontual de plantio no inverno ou uma pequena criação permitem diminuir o peso dos custos na economia familiar ${ }^{27}$. As diversas falas e depoimentos que surgiram na pesquisa tendem a se posicionar numa perspectiva em que o trabalho na confecção é requerido para complementar a renda familiar. Da mesma forma, as reuniões das associações, Sindicato de Trabalhadores Rurais e o Conselho Municipal de Desenvolvimento Rural Sustentável quando discutem essas atividades o fazem na perspectiva de alternativas, ou seja, em relação a uma forma de vida considerada entre

\footnotetext{
${ }^{26}$ A categoria camponeses-trabalhadores, conforme é apresentado por Menezes (2002), nos parece ser útil para refletir sobre esse caso. Para a autora, não se trata de uma categoria de transição, como se poderia entender como um estágio rumo a uma proletarização e urbanização, mas constitui uma adaptação permanente e de longa duração no interior da sociedade industrial

${ }^{27}$ Pode-se considerar também as obrigações de partilha entre os membros da família. Nesse caso, transcende-se os limites da comunidade ou do que é rural e proporcionaria a circulação desses gêneros alimentares junto a parentes que vivem nas cidades.
} 
os participantes desses espaços de ação coletiva. Ao mapear as cadeias e redes que configuram o trabalho na confecção, contudo, tornou-se claro que essa atividade subordina em alguma medida as demais como forma de garantir a acumulação do capital.

\section{Projetos e estratégias na unidade familiar}

O trabalho na confecção mobiliza homens e mulheres numa perspectiva de busca de alternativas para a reprodução social das unidades familiares e na construção de projetos de vida dos indivíduos. As trajetórias de mulheres que buscam se inserir nas atividades da confecção oferecem detalhes de como a unidade familiar pode se configurar neste novo contexto. Para além das redefinições internas decorrentes da copresença de atividades agrícolas e não-agrícolas, é necessário também ver como os membros individualmente interagem nessas situações, em especial projetando para si perspectivas de futuro.

Entre as mulheres com quem dialogamos, foi observado várias formas de inserção nas atividades da confecção. As irmãs Daniela (44 anos) e Vanusa (45 anos), da comunidade dos Pinhões, explicam como iniciaram sua participação na costura: segundo Daniela, era porque "não tinha inverno, [para] trabalhar no campo, aí a gente fez o curso e começou a trabalhar". O curso em questão é o de costura industrial oferecida pela administração municipal. Segundo elas, através de uma amiga ficaram sabendo da existência dele e passaram dois anos aguardando serem chamadas uma vez que a prioridade era para as pessoas da cidade, fazendo com que as da zona rural ficassem por último. Após seis meses do término do curso, elas iniciaram o trabalho na confecção. Como relata Daniela, “(...) aí depois que fez o curso, aí meu pai disse: vocês fizeram o curso, mas não vão trabalhar na cidade, não. Aí a gente pegou um garrote, vendeu e aí foi inteirando e foi comprando de uma por uma as máquinas”.

Esse depoimento revela como a estrutura familiar e as opções das suas integrantes se relacionam. A rede de conhecimento que as informou da possibilidade de acesso a uma atividade alternativa ao trabalho agrícola reflete a existência de uma cadeia na qual várias mulheres estão envolvidas e, em muitos casos, assumindo um protagonismo na sua família. No caso aqui relatado, observa-se que as escolhas foram mediadas diante da estrutura familiar. Embora não pudessem trabalhar na cidade, as irmãs Daniela e Vanusa puderam contar com os animais de propriedade da família para 
poder montar a unidade produtiva da confecção. Tal caso permite mostrar como as ações e projetos individuais tendem a ser mediados por outras esferas.

Outra forma de ingressar na atividade da confecção de vestuários é através da experiência de trabalho com parentes. É o caso de Cláudia (30 anos), residente no Mimoso. Antes de se mudar para essa localidade e iniciar uma pequena facção, ela residia na comunidade vizinha do Alegre onde trabalhou junto com uma irmã. Atualmente, ela trabalha com mais cinco pessoas, incluindo outra irmã, esta residente em Cachoeira do Taépe. Se por um lado o trabalho com a família expressa um caráter não quantificado, e em muitos casos visto como ajuda, por outro, o trabalho para a família, ou seja, dos parentes que moram em outro domicílio, tende a ser remunerado. $\mathrm{O}$ caso de Cláudia e suas irmãs pode ser entendido na perspectiva de um mecanismo de agenciamento na rede de mulheres. A possibilidade de trabalhar para um parente na confecção constitui nesse caso uma forma de buscam autonomia, tanto individual como coletiva entre o conjunto das mulheres.

Para adquirir as máquinas e, com isso, montar um fabrico ou facção, as mulheres recorrem a diversos meios. Podem comprar, através de capital próprio, adquirido com a venda de animais da propriedade, o que corresponde a um cálculo econômico familiar onde se transfere o capital da atividade agrícola para a não-agrícola. Pode vir das economias feitas pela passagem na atividade da confecção em outras localidades, ou mesmo em outros empregos. Pode também vir dos financiamentos como o Proamigo ${ }^{28}$. Francisca, moradora no Jucá Ferrado, ao explicar como adquiriu suas máquinas apresenta uma complexidade de meios para se inserir nessa atividade:

- De onde veio o capital para comprar a máquina?

- Olha, primeiro eu comprei uma máquina, eu comprei aquela pequena para ficar pagando.

- Com essa máquina já costurava para fora?

- Costurava esses mesmos shorts que já era de um rapaz [da comunidade vizinha] do Gancho do Galo. Ai eu costurava para ele. As peças eu peguei e tentei fazer. Consegui, ai fiquei pagando ao vendedor da máquina. Aí, depois ele, o rapaz para quem a gente costurava, comprava as máquinas em Santa Cruz, que nesse tempo

\footnotetext{
28 ProAmigo é o programa de microfinança rural do Banco do Nordeste do Brasil. Com esse financiamento, pode-se adquirir tanto insumos para a produção agrícola e compra de animais como instrumentos e matérias primas para a confecção de vestuários, desde que a unidade familiar mantenha $30 \%$ das suas atividades voltadas para as atividades agrícolas. Isso tem levado ao surgimento do que estamos chamando de "confeccionistas-pronafianos" (Andrade, 2017) que mantêm algum nível de atividades agrícolas como forma de ter acesso ao financiamento de atividades nas confecções.
} 
não tinha esse negócio de empréstimo. Ele comprava a máquina lá na Makital, que não tinha aqui também, era tudo em Santa Cruz. Ai ele comprava e ia descontando na costura.

- Esse rapaz no Gancho do Galo fazia isso com outras pessoas?

- Todas as costureiras dele. Ele fazia isso. A gente tava costurando e ele fazia tudo para melhorar. Quando quebrava, ele levava. Ele trazia agulha, óleo, essas coisas, ai ele descontava na costura.

- Mas enquanto aquela primeira máquina, foi comprada com economia sua?

- Foi de casa. Vendia uma galinha, qualquer coisa. Tinha porco, criava porco. Vendia o porco e comprava alguma coisa assim e ia levando.

A diversidade de meios pelos quais Francisca procurou se firmar na atividade da costura revela as condições oferecidas tanto no interior da unidade familiar como externa a ela. Como afirma, é de casa de onde veio o recurso para a compra da primeira máquina. Importante destacar que Francisca só fez empréstimos junto ao Proamigo para a compra de animais. Dessa forma, o capital investido com a venda dos animais retornou através do financiamento que por sua vez foi pago com o que ganhava na costura, estabelecendo uma troca entre as diferentes esferas de produção.

A entrega de máquinas e equipamentos sob a condição de desconto no preço das roupas produzidas é outro mecanismo que permite a integração de mão de obra nessa atividade. Constitui uma espécie de financiamento entre o contratante e o contratado. Segundo Francisca, essa prática chegou a transbordar a relação que antes era estritamente relacionada ao equipamento e produção de roupas quando outro confeccionista na qual veio a trabalhar vendia bojões de gás ao preço do desconto do valor das roupas fabricadas por ela. Ou seja, diversas práticas econômicas têm sido usadas como forma de construir possibilidades de incorporação de trabalhadoras nessa atividade e de reprodução do capital.

No território do Polo, pode-se ver que esses mecanismos podem aparecer sob outras formas. Milanês (2015) destaca a prática dos contratantes de emprestar máquinas além de entregar peças para a costura. Trata-se de uma possibilidade de empregar uma mão de obra para que trabalhem em seus domicílios quando estes só possuem sua força de trabalho.

\section{Conclusões}

Os casos aqui analisados nos mostram um processo de rápidas mudanças sociais e como diversas estratégias têm sido reelaboradas por diversos atores. O ponto 
de vista adotado de privilegiar aqueles que mais diretamente têm se envolvido nessas transformações nos oferece a possibilidade de observar todas as ambiguidades presentes. Vemos, por exemplo, quando o Estado assume a responsabilidade de promoção de um conjunto de políticas públicas de manutenção e fortalecimento de um determinado setor produtivo e que para muitas famílias essas iniciativas são estrategicamente utilizadas para outros fins. São essas (micro) ações que revelam as astúcias (De Certeau, 1998) de homens e mulheres que se mobilizam em busca de meios de sobrevivência.

Deve-se destacar também as diversas formas pelas quais o capitalismo encontra para a sua reprodução. Não necessariamente precisa suprimir as relações sociais oriundas de uma ordem moral camponesa, quando pode subordiná-las. Isso implica dizer que há uma interação entre as formas de reprodução do capitalismo e as formas pelas quais os grupos subalternos lidam com essa realidade. Diante dos projetos do capital, que se impõem e tentam delinear uma territorialidade, há que se considerar também os projetos de vida (Scott, 2013) dos grupos subalternos.

O Polo de Confecções do Agreste de Pernambuco expressa, em suas características, aquilo que Harvey (2014) entende como acumulação flexível. A forma como o território das confecções se vincula a esse padrão de reprodução do capital merece uma análise específica que este trabalho não pode dar conta. A investigação etnográfica, contudo, permite-nos fazer algumas breves considerações. Seria limitado tomar a economia moral de populações - no caso aqui analisado de agricultores de base familiar - como um simples contraponto e possibilidade de alternativas a um padrão hegemônico de reprodução do capital. Do ponto de vista das interações socioeconômicas, é importante destacar como as atividades agrícolas e não-agrícolas se relacionam. Nesse caso, pode-se perceber que mesmo as atividades que ocupam um peso cada vez mais reduzido na economia doméstica como a criação e o plantio para o consumo interno permitem que a força de trabalho não dependa exclusivamente da remuneração vinda do trabalho na confecção. O que não quer dizer que as condições de trabalho sejam melhores. Nesse sentido, nos parece interessante o que diz Kofti (2016), a partir de sua pesquisa etnográfica em uma fábrica de vidros na Hungria, de que as diversas hierarquias morais de valor podem convergir no local de trabalho contribuindo para a reprodução da precariedade e do capital sob formas flexíveis. É nesse sentido que 
se deve compreender os padrões de residência e relações de vizinhança nos espaços rurais que permitem que os filhos fiquem sob os cuidados de parentes próximos garantindo que a mão de obra feminina seja liberada. Também permite entender a importância da ajuda, um mecanismo que torna invisível o trabalho de mulheres e crianças no interior de uma unidade produtiva e que mobiliza grande número de integrantes da família para trabalharem nas confecções sem que, com isso, implique em um assalariamento ou remuneração individual de todos.

\section{Referências Bibliográficas}

ANDRADE, Berlano Bênis França de. Tem que saber se movimentar: trabalho, mobilidades e estratégias de famílias rurais no território das confecções no Agreste Pernambucano. Dissertação de Mestrado em Antropologia. Universidade Federal de Pernambuco, 2017.

BURNETT, Annahid. "As raízes rurais da Feira da Sulanca no Agreste pernambucano" Revista Extensão Rural, DEAER - CCR - UFSM. v.21, n.4, out./dez, 2014.

CARNEIRO, Maria José; PEREIRA, Jorge Luiz de Goes. "Tecendo novas estratégias: confecções em domicílios rurais em Nova Friburgo" In CARNEIRO, Maria José (coord.) Ruralidades contemporâneas: modos de viver e de pensar o rural na sociedade brasileira. Rio de Janeiro, Mauad X - Faperj, 2012.

CHAYANOV, Alexander V. La organización de la unidad econômica campesina. Buenos Aires, Nueva Visión, 1985.

De CERTEAU, Michel. A invenção do cotidiano I: artes de fazer. Petrópolis, Vozes: $3^{\mathrm{a}}$ ed., 1998.

ESPÍRITO SANTO, Wecisley Ribeiro do. Sulanqueiras. O trabalho com vestuário e outros ofícios no Agreste Pernambucano. Tese de Doutorado em Antropologia Social. Universidade Federal do Rio de Janeiro, 2013.

FUSCO, Wilson; VASCONCELOS, Valtemira Mendes. Migrantes e costureiros: trabalhadores do setor de confecções em Toritama-Pe. Cadernos de Estudos Sociais. 25 (1): 43-60, 2010. 
GARCIA JR, Afrânio Raul. Terra e trabalho: trabalho familiar de pequenos produtores. Rio de Janeiro, Paz e Terra, 1983.

. O Sul: caminho do roçado: estratégias de reprodução camponesa e transformação social. São Paulo, Editora Marco Zero; Brasília, Editora UNB, 1990.

GOMES, Sueli de Castro. Dissertação de Mestrado em Geografia. Universidade de São Paulo, 2002.

HARVEY, David. O enigma do capital e as crises do capitalismo. São Paulo, Boitempo Editorial, 2011.

. A Condição Pós-Moderna. São Paulo, Edições Loyola: 25ª Ed., 2014.

HEREDIA, Beatriz M. A. de. A morada da vida: trabalho familiar de pequenos produtores do Nordeste do Brasil. Rio de Janeiro, Paz e Terra, 1979.

KOFTI, Dimitra. "Moral economy of flexible production: Fabricating precarity between the conveyor belt and the household". Anthropological Theory, 16(4) : 433-453, 2016.

LIRA, Sonia Maria. Muito Além das Feiras da Sulanca: a produção de confecção no Agreste/PE. Recife, Editora Universitária UFPE, 2011.

LIMA, Jacob Carlos; SOARES, Maria José Bezerra. "Trabalho flexível e o novo informal" Caderno CRH n. 37: 163-180, 2002.

LYRA, Maria. "Sulanca X muamba: rede social que alimenta a migração de retorno" São Paulo em Perspectiva, São Paulo, v. 19: 144-154, 2005.

MELO, Mario Lacerda de. Os Agrestes: estudos dos espaços nordestinos do sistema gado-policultura de uso de recursos. Recife, SUDENE, 1980.

MENEZES, Marilda A. Redes e enredos nas trilhas dos migrantes: um estudo de famílias de camponeses-migrantes. Rio de Janeiro, Relume Dumará; João Pessoa, EDUFPB, 2002.

- "Migrações: uma experiência histórica do campesinato do Nordeste", In GODOI, Emília Pietrafesa de; MENEZES, Marilda A; MARIN, Rosa Acevedo (orgs.). Diversidade do campesinato: expressões e categorias, v. 2: estratégias 
de reprodução social. São Paulo, UNESP; Brasília, Núcleo de Estudos Agrários e Desenvolvimento Rural, 2009.

MILANÊS, Renata B. Costurando roupas e roçados: as linhas que tecem trabalho e gênero no Agreste pernambucano. Dissertação de Mestrado em Ciências Sociais em Desenvolvimento, Agricultura e Sociedade. Universidade Federal Rural do Rio de Janeiro, 2015.

RABOSSI, Fernando. "Em la uta de las confecciones". Revista Crítica en Desarrollo. 02: 151-171, 2008.

RIBEIRO, Gustavo Lins. A Globalização Popular e o Sistema Mundial Não Hegemônico. Série Antropologia Vol. 432, Brasília: DAN/UnB, 2009.

SCOTT, James C. "Formas cotidianas da resistência camponesa". Raízes, 21, 1: 10-31, 2002 .

SCOTT, Russell Parry. “A Lógica Migratória Camponesa Sob O Capital” In DUARTE, Renato. (Org.). Emprego rural e migração na América Latina. Recife, MASSANGANA, 1986.

- "Projetos de desenvolvimento no rio São Francisco: administrando vocações e desigualdades" Campos 14(1-2): 15-36, 2013.

- Migrações interregionais estratégia doméstiva: Nordestinos, mobilidades e a casa até os anos 1980. Recife, Editora Universitária UFPE, 2014.

SEBRAE. Estudo econômico do arranjo produtivo local de confecções do Agreste pernambucano. Recife, SEBRAE, 2013.

SILVA, Maria Regina M. Batista e. O universo da bordadeira: estudo etnográfico do bordado em Passira. Dissertação de Mestrado em Antropologia Cultural. Universidade Federal de Pernambuco, 1995.

SILVA, Sandra Roberta. A juventude na "Sulanca": Os desafios da inserção no mundo do trabalho em Taquaritinga do Norte - PE. Dissertação de Mestrado em Ciências Sociais. Universidade Federal de Campina Grande, 2009.

SOUZA, Alana Moraes de. "A gente trabalha onde a gente vive”: A vida social das relações econômicas: parentesco, "conhecimento" e as estratégias econômicas no 
Agreste das confecções. Dissertação de Mestrado em Antropologia. Programa de Pósgraduação em Sociologia e Antropologia. Universidade Federal do Rio de Janeiro, 2012.

VAN VELSEN, J. "A análise situacional e o método de estudo de caso detalhado" In FELDMAN-BIANCO. Bela (org.) Antropologia das sociedades contemporâneas: métodos. São Paulo, Editora Unesp, 2010.

VÉRAS DE OLIVEIRA, Roberto. "O pólo de confecções do agreste de Pernambuco: ensaiando uma perspectiva de abordagem" In: 35 Encontro Anual da ANPOCS, 2011, Caxambu. Anais do $35^{\circ}$ Encontro Anual da Anpocs. São Paulo, Anpocs, 2011.

WOORTMANN, Klaas. "Migração Família e Campesinato", In WELCH, Clifford A [et al.] Camponeses brasileiros: Leituras e interpretações clássicas, vol. I. São Paulo, UNESP; Brasília, Núcleo, 2009.

Recebido 20/02/2020

Aprovado 10/04/2020 